\title{
The Efficacy of Coblator in Turbinoplasty
}

\author{
Keun-Cheol Lee ${ }^{1}$, \\ Jeong-Min $\mathrm{Cho}^{1}$, \\ Seok-Kwun Kim ${ }^{1}$, \\ Kwang-Ryeol Lim, \\ Sang-Yun Lee ${ }^{1}$, \\ Su-Seong Park ${ }^{2}$ \\ ${ }^{1}$ Department of Plastic and Reconstructive Sur- \\ gery, Dong-A University School of Medicine, \\ Busan; \\ ${ }^{2} I \& C o$ Aesthetic Plastic Surgery Clinic, Busan, \\ Korea
}

\begin{abstract}
Background: Turbinate hypertrophy is one of the common causes of chronic nasal obstruction. In principle, therapeutic guidelines recommend medical treatment. Failure to treat turbinate thickening despite drug therapy may indicate the need for surgery. The main aim of this study was to determine the effect of radiofrequency surgery, among various other surgical procedures, on people with both nasal septal deviation and turbinate hypertrophy. Methods: Among people with nasal deviation who visited the subject hospital between July 2008 to July 2014, 21 people with nasal septal deviation and severe turbinate hypertrophy before their surgery had undergone septoplasty with turbinoplasty using radiofrequency combined with septoplasty. The degree of the turbinate's hypertrophy was appraised in all the patients before and after the surgery using the rhinoscopy, and acoustic rhinometry was objectively carried out. The subjective effect of the turbinoplasty using radiofrequency was explored through the visual analog scale (VAS) score.

Results: The degree of contraction of the nasal mucosa after the rhinoscopy changed from Grades 3 and 4 (100\%) to Grades 1 and 2 (95.2\%) and Grades $3(4.8 \%)$. The minimal cross-sectional area significantly increased from $0.44 \pm 0.07$ to $0.70 \pm 0.07 \mathrm{~cm}^{2}(p<0.05)$. The nasal cavity volume increased from $4.79 \pm 0.49$ to $6.76 \pm 0.55 \mathrm{~cm}^{2}(p<0.05)$. The subjective symptoms evaluated with VAS score a year after the surgery significantly improved $(p<0.05)$.

Conclusion: Turbinoplasty using Coblator with septoplasty is an effective treatment method because it expands nasal cavity, has a low incidence of complications, subjectively improves symptoms, and has short treatment duration.
\end{abstract}

Keywords: Turbinates / Nasal obstruction / Rhinoplasty / Nasal cavity
No potential conflict of interest relevant to this article was reported. nasal obstruction, pain, sleep disorder, and hyposmia [3]. These symptoms in people with turbinate hypertrophy degrade their quality of life and induce functional disorders $[1,4]$. Thus, they must be correctly treated.

Oral decongestant and local steroids are first-line treatments for turbinate hypertrophy. Failure to treat turbinate thickening despite such drug therapy may indicate the need for surgery. The surgical interventions include chemical cautery, cryosurgery, electrocautery, laser surgery, subtotal turbinectomy, submucous resection, and radiofrequency ablation. Because each of these interventions has both advantages and disadvantages, the intervention best suitable for the patient's medical condition should be chosen [4-8]. Radiofrequency ablation is performed by inserting electrodes into tissues, which produces radiofrequency currents. These currents induce coagulative necrosis and fibrotic atrophy

\footnotetext{
Correspondence: Keun-Cheol Lee

Department of Plastic and Reconstructive Surgery, Dong-A University School of Medicine, 26 Daesingongwon-ro, Seo-gu, Busan 49201, Korea

E-mail: pokdungi@dau.ac.kr

*This study was supported by research funds from Dong-A University.

*This study was presented at the 5th Research \& Reconstructive Forum.

Received December 14, 2016 / Revised April 5, 2017 / Accepted April 10, 2017
} 
around tissues, and this necrosis induces healing which eventually decreases the volum of the inflammation-caused edema. Moreover, this procedure can conserve nasal mucosa and minimizes postoperative complication and discomfort [3]. This study was conducted to discover the effect of radiofrequency surgery, among various surgical methods, on people with both nasal septum deviation and turbinate hypertrophy.

\section{METHODS}

\section{Clinical subjects}

Among the people with nasal deviation who visited the subject hospital between July 2008 to July 2014, 21 people with nasal septal deviation and severe turbinate hypertrophy had undergone septoplasty with turbinoplasty using radiofrequency (average age, 30.7 years; 11 male and 10 female). People with history of nose surgery, allergic rhinitis, drug-induced rhinitis, or nasal polyposis were excluded. All the patients were diagnosed with nasal septal deviation and turbinate hypertrophy through acoustic rhinometry, imaging examination, or Cottle test, which assesses an improvement in nasal obstruction by laterally pulling the patient's cheek and then opening his or her anterior nasal nares. The degree of turbinate thickening in the 25\% inferior turbinate classification system [9] was higher than Grade 3 (Table 1). Before the surgery, no improvement in the symptoms after pharmacological treatment was reported, and the mean period of the pharmacological treatment was 3.2 months.

\section{Procedure}

All the patients underwent standardized septoplasty $[10,11]$ under general anesthesia. Prior to the surgery, consultation on proce-

Table 1. 25\% (Grades 1-4) inferior turbinate classification system

\begin{tabular}{lc} 
Grade & Turbinate/Total airway spacex100 (\%) \\
Grade 1 & $0-25$ \\
Grade 2 & $26-50$ \\
Grade 3 & $51-75$ \\
Grade 4 & $76-100$ \\
\hline
\end{tabular}

dures was conducted with all the patients, and the entire surgical procedures were performed by one skilled operator who had more than 20 years of experience in rhinoplasty. The turbinoplasty treatment was conducted using the radiofrequency method. The tip is a 22-gauge electrode and the electrode placed into the anterior-inferior portion of the hypertrophic turbinate. The coagulation power level was set at grade three for 10-15 seconds after inserting an electrode into a thickened mucous membrane using the ENTex Coblator plasma surgery system (Arthrocare, Sunnyvale, CA, USA). A nasal endoscope was used to secure a field of view for the nasal cavity, and turbinates were assessed to insert an electrode to a proper location. The electrode was inserted one or two times to prevent any damages to the nasal mucosa. After the surgery, the nasal cavity was packed using local vasoconstrictor.

\section{Clinical outcomes}

The degrees of atrophy of the turbinate due to the rhinoscopy before the surgery and one month after the surgery were evaluated using the 25\% inferior turbinate classification system [9]. The incidence of complications such as hemorrhage, incrustation, and synechia one month after the surgery was investigated, and the stability of the surgery was assessed. The minimal cross-sectional area (MCA) and the nasal cavity volume (NCV) were evaluated using acoustic rhinometry before the surgery and one year after the surgery. The acoustic rhinometry was performed with the Eccovision Acoustic Rhinometer (Model AR-1003, Hood Laboratories, Pembroke, MA, USA) by first asking the patient to sit in a comfortable position, and then maintaining approximately 15-degree angle between the patient's body and the major axis of the nosepiece, before asking the patient to hold his or her breath. Moreover, the severity of the nasal obstruction, headache, and hyposmia in the patients was evaluated using the $10 \mathrm{~cm}$ visual analog scale (VAS) before the surgery and three, six, nine, and 12 months after the surgery.

\section{Statistical analysis}

The acoustic rhinometric results before the surgery and 12 
months after the surgery were statistically analyzed using the paired t-test. Repeated analysis of variance was conducted to analyze the chronologic difference of nasal obstruction, headache and hyposmia 3, 6, 9 and 12 months after surgery. All of the statistical tests were regarded at significant at $p<0.01$ and were performed using SPSS ver. 22.0 (IBM, Armonk, NY, USA).

\section{RESULTS}

Twenty-one patients (average age, 30.7 years; 11 male and $10 \mathrm{fe}$ male) underwent septoplasty and turbinoplasty using radiofrequency. They were treated with drug therapy for an average of 3.2 months and all the patients' sign and symptoms were not resolved. So surgical treatment was considered. Before the surgery, eight patients with Grade 3 and 13 patients with Grade 4 were observed with the $25 \%$ inferior turbinate classification system. A month after the surgery, the degree of contraction of the nasal mucosa was evaluated using rhinoscopy. Fifteen patients with Grade 1 (71.4\%), 5 patients with Grade 2 (23.8\%), one patient with Grade 3 (4.8\%) were shown in the $25 \%$ inferior turbinate classification system (Table 2).

Acoustic rhinometry was performed before the surgery and 12 months after the surgery. The MCA increased from $0.44 \pm 0.07 \mathrm{~cm}^{2}$ before the surgery to $0.7 \pm 0.07 \mathrm{~cm}^{2} 12$ months after the surgery,

Table 2. Comparison of the $25 \%$ inferior turbinate classification system before the surgery with that one month after the surgery

\begin{tabular}{lcc} 
& \multicolumn{2}{c}{ Number } \\
\cline { 2 - 3 } Grade & Preoperative (\%) & Postoperative (\%) \\
Grade 1 & 0 & $15(71.4)$ \\
Grade 2 & 0 & $5(23.8)$ \\
Grade 3 & $8(38.1)$ & $1(4.8)$ \\
Grade 4 & $13(61.9)$ & 0 \\
\hline
\end{tabular}

Table 3. Statistical analysis of the changes in the MCA and the NCV

\begin{tabular}{lcc} 
& \multicolumn{2}{c}{ Number } \\
\cline { 2 - 3 } Grade & Preoperative (\%) & Postoperative (\%) \\
Grade 1 & 0 & $15(71.4)$ \\
Grade 2 & 0 & $5(23.8)$ \\
Grade 3 & $8(38.1)$ & $1(4.8)$ \\
Grade 4 & $13(61.9)$ & 0 \\
\hline
\end{tabular}

MCA, minimal cross-sectional area; NCV, nasal cavity volume. which show a statistically significant difference (Table 3) (Fig. 1) $(p<0.05)$. The change in the NCV significantly increased from 4.79 $\pm 0.49 \mathrm{~cm}^{2}$ before the surgery to $6.76 \pm 0.55 \mathrm{~cm}^{2} 12$ months after the surgery $(p<0.05)$ (Table 3) (Fig. 2).

The incidence of nasal obstruction, headache, and hyposmia in the patients was evaluated using the VAS score three, six, nine, and 12 months after the surgery. The degree of the nasal obstruction in the VAS was scored $7 \pm 1.3$ before the surgery, $2.05 \pm$ 0.67 three months after the surgery, $2.29 \pm 0.46$ six months after

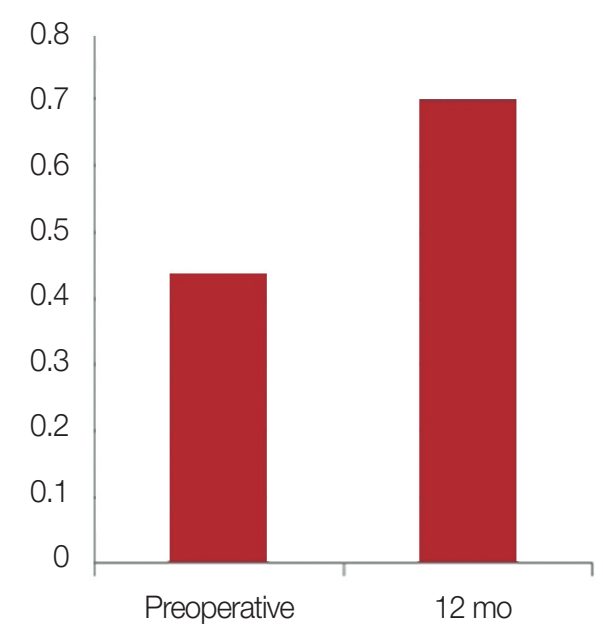

Fig. 1. Comparison of the MCA before the surgery with that after the surgery using acoustic rhinometry. MCA, minimal cross-sectional area.

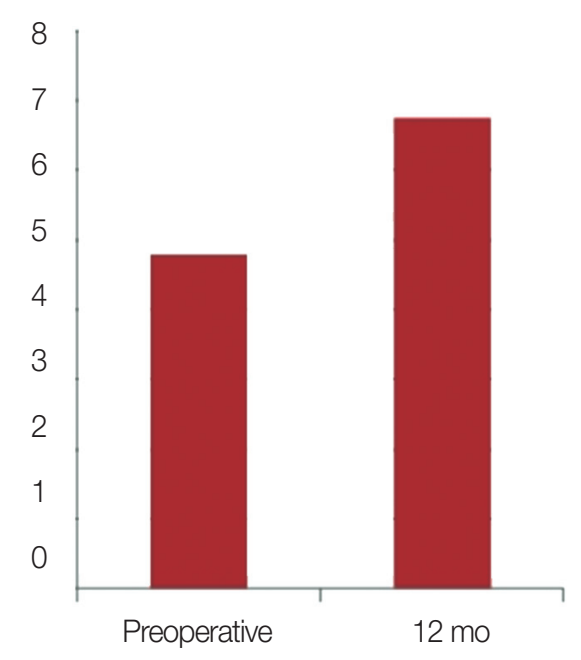

Fig. 2. Comparison of the nasal cavity volume (NCV) before the surgery with that after the surgery using acoustic rhinometry. 
the surgery, $2.43 \pm 0.51$ nine months after the surgery, and $2.52 \pm$ 0.51 one year after the surgery, which show an average reduction of $64.0 \%$. The frequency of headaches was scored $5.9 \pm 1.3$ before the surgery, $1.95 \pm 0.8$ three months after the surgery, $1.95 \pm 0.74$ six months after the surgery, $2 \pm 0.55$ nine months after the surgery, and $2.38 \pm 0.74$ a year after the surgery, which show an average reduction of $59.7 \%$. The degree of hyposmia was scored 6.33 \pm 1.15 before the surgery, $2.00 \pm 0.71$ three months after the surgery, $1.90 \pm 0.44$ six months after the surgery, $2.24 \pm 0.44$ nine months after the surgery, and $2.76 \pm 0.7$ a year after the surgery, which show an average reduction of $56.4 \%$. The degree of severity of the symptoms, such as nasal obstruction, headache and hyposmia significantly decreased after the surgery $(p<0.05)$ (Table 4) (Fig. 3). Furthermore, a month after the surgery, complications such as hemorrhage, incrustation, and synechia were not observed.

\section{DISCUSSION}

When the nasal septum is deviated toward one side, an expanded space of the nasal cavity on the opposite side is filled with turbinate hypertrophy [12]. This causes the symptom of nasal obstruction also in the curved nasal cavity on the opposite side. As a result, if septoplasty only is performed, the improvement of the symptom may wane due to the hypertrophied turbinate on the opposite side. For this reason, there have recently been more and more cases where septoplasty is performed together with turbinoplasty, and the effects of this method have been proved in many literatures $[12,13]$. Turbinoplasty includes a variety of methods, ranging from total turbinectomy to radiofrequency ablation or microdebrider-assisted turbinoplasty, that have their own strengths and weaknesses. Among these methods, coblator-assisted turbinoplasty is easy to perform and causes fewer compli-

Table 4. Statistical analysis of the VAS

\begin{tabular}{lcccccc} 
& Preoperative & 3 mo & 6 mo & 9 mo & 12 mo & $p$-value \\
Nasal obstruction & $7.00 \pm 1.30$ & $2.05 \pm 0.67$ & $2.29 \pm 0.46$ & $2.43 \pm 0.51$ & $2.52 \pm 0.51$ & $<0.001$ \\
Headache & $5.90 \pm 1.30$ & $1.95 \pm 0.80$ & $1.95 \pm 0.74$ & $2.00 \pm 0.55$ & $2.38 \pm 0.74$ & $<0.001$ \\
\hline Hyposmia & $6.33 \pm 1.15$ & $2.00 \pm 0.71$ & $1.90 \pm 0.44$ & $2.24 \pm 0.44$ & $2.76 \pm 0.70$ & $<0.001$ \\
\hline
\end{tabular}

VAS, visual analog scale.

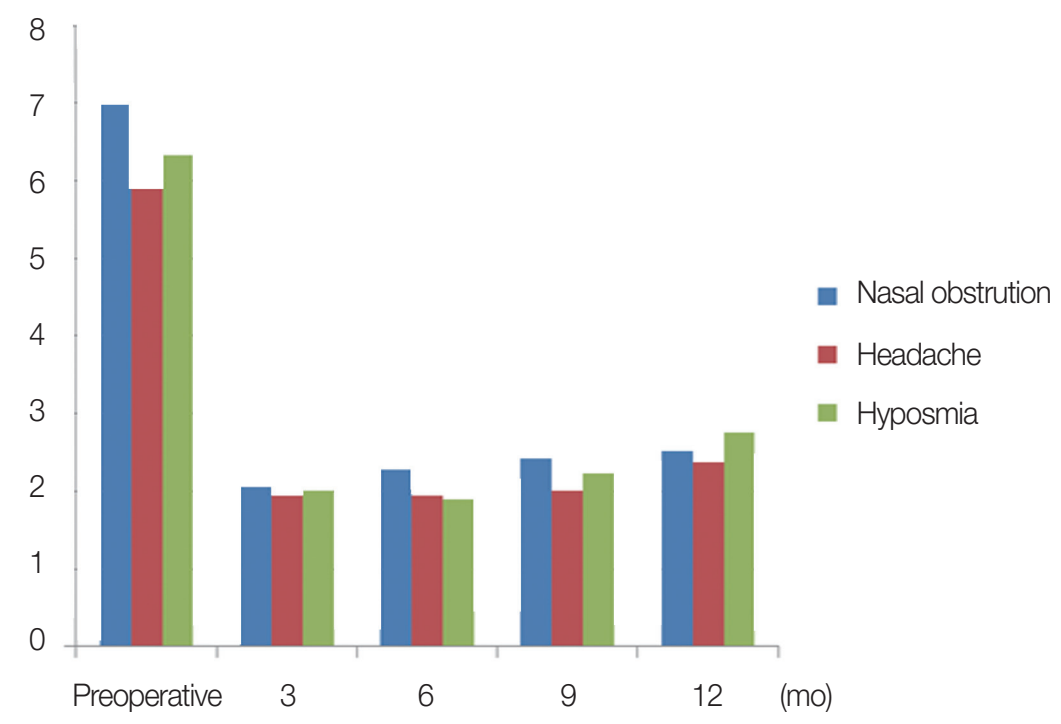

Fig. 3. Comparison of the symptoms before the surgery with those three, six, nine, and 12 months after the surgery using the VAS score. VAS, visual analog scale. 
cations with higher effects so that it has been widely used. However, there have not been many studies that objectively prove the effects of performing septoplasty and turbinoplasty simultaneously in the area of plastic surgery. In particular, because noses of Asian people are different from those of Western people, the significance of this study is to find out the effects of septoplasty and coblator-assisted turbinoplasty in an objective manner when these two are performed simultaneously for Koreans.

Mahler and Reuven [14] mentioned that additional turbinoplasty surgery along with septoplasty may inhibit nasal cavity reduction after surgery. Turbinoplasty was performed using Coblator. Radiofrequency ablation is more effective and safer procedure in inferior turbinate hypertrophy than other conventional turbinoplasty technique [3-5]. Traditional turbinoplasty is an effective surgical treatment for inferior turbinate hypertrophy, which causes acoustic airway obstruction. Yet, after surgery, such complications as pain, hemorrhage, and incrustation may occur [8]. To reduce the risk of these complications, turbinoplasty surgery with radiofrequency has been introduced. Nease and Krempl [15] mentioned that frequency and severity of nasal obstruction significantly reduced in the symptom analysis with VAS, eight weeks after the turbinoplasty surgery using Coblator. Abdel-Fattah et al. [8] comparatively analyzed the effect of the radiofrequency, submucosal resection, and traditional turbinoplasty treatments on the thickened mucus membrane reduction. In this study, as the turbinoplasty using radiofrequency was performed under local anesthesia, its procedure was simple and it had a low risk of complications. However, the effect shown in the long-term follow-up observation tended to wane.

For the objective measurement of results when septoplasty and turbinoplasty were performed at the same time, changes in the area and volume of the nasal cavity were examined by using acoustic rhinometry for all the patients. Acoustic rhinometry is useful in measuring the size of the nasal cavity using the reflection of a sound wave. Cakmak et al. [16] said the excellent reproducibility and accuracy of acoustic rhinometry make it a valuable method of evaluating the measurement of acoustic airway obstruction. McCaffrey and Kern [17] stated that acoustic rhinometry is a valuable test because it is non-invasive and fast, and can be performed with minimal cooperation.

Visual analog scale (VAS) was used to objectively assess the degree of improvement in patients' subjective symptoms. The VAS is an objective measurement tool for evaluating the degrees of the symptoms of a patient. Wewers and Lowe [18] said it is effective in determining the changes in personal symptoms. Lund [19] said it can be a critical indicator of change and evaluator of symptoms of people with nasal obstruction. Fisher et al. [20] and Roithmann et al. [21] respectively compared changes in MCA and VAS before and after a nasal mucosa astringent was administered for normal people and patients. Based on the comparison results, they reported that changes in the MCA on one side had a significant correlation with changes in nasal obstruction on the same side. The results of this study also found that the symptom score, the MCA and the NCV of patients showed improvement with statistical significance after septoplasty and coblator-assisted turbinoplasty were conducted simultaneously. Performing septoplasty and coblator-assisted turbinoplasty simultaneously leads to increases in the numbers of the MCA and NCV, which means the structural expansion of the nasal cavity. These significant changes demonstrate a possibility for improvement in nasal breathing, which will increase the level of a patent's satisfaction after surgery.

This study had the limitation of not having included a control group but only patients who had undergone septoplasty with turbinoplasty using Coblator. There are various other turbinoplasty treatment methods, including submucosal resection and traditional turbinoplasty. However, the effects of these methods cannot be compared because they were not performed simultaneously in this study. Therefore, septoplasty with turbinoplasty using Coblator cannot be determined as the best treatment method for nasal cavity expansion and symptom improvement. A further comparative analysis of various methods is crucial.

Furthermore, as the septoplasty treatment was performed with turbinoplasty, the effect was very difficult to attribute to either septoplasty or turbinoplasty alone. Moxness and Nordgard [22] conducted a comparative cohort study of the degree of improvement of the symptoms in patients with sleep apnea between the patients treated with both septoplasty and turbinoplasty and the 
patients treated only with septoplasty. He asserted that septoplasty treatment with turbinoplasty effectively improved the symptoms. However, the improvement of the other symptoms such as nasal obstruction, headache, and hyposmia were not studied. Thus, further research is needed with a control group.

The degree of severity of the subjective symptoms such as nasal obstruction, rhinorrhea, headache, and hyposmia can differ from patient to patient. Moreover, the assessment using VAS may distort the degree and prevalence of the symptoms in a day or a year. More subjects are required to compensate for such distortion.

In this study, the degree of improvement of the patients' symptoms using VAS and the degree of expansion of the nasal cavity using acoustic rhinometry were significantly enhanced (Fig. 3). Because the VAS three, six, nine, and 12 months after the surgery tended to gradually increase, the turbinate may thicken in time. That is, the recurrence and incidence of the symptoms of turbinate hypertrophy must be evaluated through long-term follow-up observation for over a year.

In the cases of septoplasty and turbinoplasty using Coblator, the acoustic rhinometry significantly increased the nasal cavity volume. Also, the subjective symptoms of the patients were significantly relieved according to the VAS. Therefore, septoplasty with turbinoplasty operation using Coblator relieves symptoms and improves the quality of life of people with nasal deviation who suffer from severe nasal obstruction. But, symptomes after the surgery tended to gradually increase and the turbinate may thicken in time. Therefore, the recurrence and incidence of the symptoms of turbinate hypertrophy must be evaluated through longterm follow-up observation for over a year. If it is determined that turbinate hypertrophy has actually recurred, the patient may undergo a second operation under local anesthesia at an outpatient clinic.

\section{REFERENCES}

1. Lavinsky-Wolff M, Camargo HL Jr, Barone CR, Rabaioli L, WolffFH, Dolci JE, et al. Effect of turbinate surgery in rhinoseptoplasty on quality-of-life and acoustic rhinometry outcomes: a randomized clinical trial. Laryngoscope 2013;123:82-9.

2. Berger G, Hammel I, Berger R, Avraham S, Ophir D. Histopathology of the inferior turbinate with compensatory hypertrophy in patients with deviated nasal septum. Laryngoscope 2000;110:2100-5.

3. Cingi C, Ure B, Cakli H, Ozudogru E. Microdebrider-assisted versus radiofrequency-assisted inferior turbinoplasty: a prospective study with objective and subjective outcome measures. Acta Otorhinolaryngol Ital 2010;30:138-43.

4. Liu CM, Tan CD, Lee FP, Lin KN, Huang HM. Microdebrider-assisted versus radiofrequency-assisted inferior turbinoplasty. Laryngoscope 2009;119:414-8.

5. Lee KC, Hwang PH, Kingdom TT. Surgical management of inferior turbinate hypertrophy in the office: Three mucosal sparing techniques. Operative Techniques in Otolaryngology-Head and Neck Surgery 2001;12:107-11.

6. Gindros G, Kantas I, Balatsouras DG, Kaidoglou A, Kandiloros D. Comparison of ultrasound turbinate reduction, radiofrequency tissue ablation and submucosal cauterization in inferior turbinate hypertrophy. Eur Arch Otorhinolaryngol 2010;267:1727-33.

7. Sathyaki DC, Geetha C, Munishwara GB, Mohan M, Manjuanth K. A comparative study of endoscopic septoplasty versus conventional septoplasty. Indian J Otolaryngol Head Neck Surg 2014;66:155-61.

8. Abdel-Fattah AM, Eid MI, Ezzat AE. Turbinoplasty using submucosal microdebrider, radiofrequency and conventional surgical, what is the best? Online J Otolaryngol 2014;4:117-28.

9. Camacho M, Zaghi S, Certal V, Abdullatif J, Means C, Acevedo J, et al. Inferior turbinate classification system, grades 1 to 4: development and validation study. Laryngoscope 2015;125:296-302.

10. Fettman N, Sanford T, Sindwani R. Surgical management of the deviated septum: techniques in septoplasty. Otolaryngol Clin North Am 2009;42:241-52.

11. Edwards N. Septoplasty. Rational surgery of the nasal septum. J Laryngol Otol 1975;89:875-97.

12. Grymer LF, Illum P, Hilberg O. Septoplasty and compensatory inferior turbinate hypertrophy: a randomized study evaluated by acoustic rhinometry. J Laryngol Otol 1993;107:413-7.

13. Lee TH, Kim BY, Kim DY. Effectiveness of the turbinoplasty in the patient with deviated septum of nose. Korean J Otolaryngol-Head Neck Surg 2005;48:326-31.

14. Mahler D, Reuven S. The role of turbinectomy in rhinoplasty. Aesthetic Plast Surg 1985;9:277-9.

15. Nease CJ, Krempl GA. Radiofrequency treatment of turbinate hypertrophy: a randomized, blinded, placebo-controlled clinical trial. Otolaryngol Head Neck Surg 2004;130:291-9.

16. Cakmak O, Coskun M, Celik H, Buyuklu F, Ozluoglu LN. Value of acoustic rhinometry for measuring nasal valve area. Laryngoscope 2003;113:295-302.

17. McCaffrey TV, Kern EB. Clinical evaluation of nasal obstruction: a study of 1,000 patients. Arch Otolaryngol 1979;105:542-5.

18. Wewers ME, Lowe NK. A critical review of visual analogue scales in the measurement of clinical phenomena. Res Nurs Health 1990; 13:227-36.

19. Lund VJ. Evidence-based surgery in chronic rhinosinusitis. Acta Oto- 
laryngol 2001;121:5-9.

20. Fisher EW, Scadding GK, Lund VJ. The role of acoustic rhinometry in studying the nasal cycle. Rhinology 1993;31:57-61.

21. Roithmann R, Cole P, Chapnik J, Barreto SM, Szalai JP, Zamel N. Acoustic rhinometry, rhinomanometry, and the sensation of nasal patency: a correlative study. J Otolaryngol 1994;23:454-8.

22. Moxness MH, Nordgard S. An observational cohort study of the effects of septoplasty with or without inferior turbinate reduction in patients with obstructive sleep apnea. BMC Ear Nose Throat Disord 2014;14:11. 